\title{
The effects of home and school on children's happiness: a structural equation model
}

\author{
Masood Badri', Ali Al Nuaimi, Yang Guang, Yousef Al Sheryani and Asma Al Rashedi
}

*Correspondence:

Masood.Badri@adek.

abudhabi.ae

Abu Dhabi Department

of Education \& Knowledge,

Abu Dhabi, UAE

\begin{abstract}
This study analyzed the structural relationships between the important constructs of school, home and family, and the happiness of Abu Dhabi school children. Survey data were collected from students in schools in the three regions of Abu Dhabi. The final dataset from 14,837 students was analyzed. Structural equation modeling (SEM) and MANOVA were employed in the study. SEM examined the association between latent constructs. For SEM, goodness of fit indices for the hypothetical model were good, and all paths were significant. The model incorporating both indirect and direct impact of home-related variables, such as how much fun did one have with their family, how did the family members get along, and how much time parents spent with their children, on the happiness of Abu Dhabi school children is valid. MANOVA showed that for all constructs, significant differences existed with regard to student gender, grade level, school location, school type, and nationality.
\end{abstract}

\section{Introduction}

Happiness is often used as a term of subjective well-being in psychology (Lyubomirsky et al. 2005a; Sagiv et al. 2004; Sheldon and Lyubomirsky 2004). If thought of in another way, happiness is an emotion combined with other positive emotions, resulting in subjective well-being when the positive emotions of a person are much more than his negative emotions, and his life satisfaction is high (Diener 2000). It is widely believed that happiness has an important and essential role in the well-being and motivation of school children (Datu et al. 2017; Frey and Stutzer 2002; Moos et al. 2005; Oreopoulos 2007; Soleimani and Tebyanian 2011). School children often face multiple challenges that may lead to negative effects and problem behaviors (Weissberg et al. 2003). The lack of happiness and joyfulness has a significant influence on students' personality growth and might affect their intelligence, thinking skills, creativity, and educational achievements (Al-Yasin 2001). Data regarding the happiness of school children should be analyzed and effectively used to meet the challenges.

The lack of happiness in schools is a major problem of many education systems, which is rarely considered in a careful manner (Guilherme and de Freitas 2017; Salavera et al. 2017). Attention to happiness should be stressed as early in childhood as possible but definitely no later than adolescence, given the importance of the cognitive, emotional, 
personality, and social development features and skills that occur during this time period (Mahon et al. 2010; Parker and Asher 1989). As early changes create a strong basis for positive happiness throughout life, most intervention programs tend to stress that educators can be influential in building positive resources for children if the changes are sought earlier. Hence, the role of family, home, and friends become vital (Kocayörük and Telef 2015; Roberts et al. 2005).

Policy makers at the Abu Dhabi Department of Education and Knowledge (ADEK) have emphasized continuously that ensuring that school children are happy and feel good about themselves will lead to much better chances of achieving the success wanted. This study aims to help school decision makers to better understand the significant determinants of happiness. This article contributes to several strands of literature in school happiness. To the best of our knowledge, this is the first study providing a structural equation model incorporating all three constructs of happiness, school-related variables, and home-related variables. It adds to the literature studying the determinants of school children happiness looking at schools of a developing country particularly in Abu Dhabi. This study mainly aims to understand what makes for happiness among school children in Abu Dhabi. The study rests largely on evidence from the Happiness of School Children Survey, which was conducted during the third semester of 2016 in Abu Dhabi. The main measures of subjective happiness are linked with student's experiences at home and school.

\section{Review of literature and conceptual framework}

There are three main theories of happiness: set-point theory, comparison theory, and affect theory, which provide different accounts for happiness (Veenhoven 2006). Setpoint theory views happiness as a stable attitude toward life that is biologically encoded in humans. It suggests that no matter what we do, we end up staying within a certain, stable level of satisfaction (Lykken 1999). Comparison theory expresses happiness as a continuous judgment process involving the comparison of our life as it relates to a perceived "ideal life". In this sense, happiness is mainly the product of our mental evaluation rather than the circumstances in which we live (McDowell and Newell 1996 pp. 204). Affect theory defines happiness as a sum of the experienced pleasures and pains (Kahneman and Tverski 2000).

The conceptual framework for school happiness stems broadly from UNESCO's mandate to promote peace through education, and in particular from important pillars of learning, mainly learning to live together and learning to be. Those pillars include qualities that are essentially based on relationships, including empathy, tolerance, respect for diversity, communication and teamwork (UNESCO 2014, 2016). The pillars also refer to qualities such as creativity, critical thinking, self-motivation, perseverance and optimism (Faure 1972). The framework also draws on elements of positive psychology, in which the core theoretical concept of well-being is positive emotion, engagement, relationships, meaning and accomplishment (Seligman et al. 2009). Given this framework, there are many definitions of school happiness that are stressed in general. Carr (2004) believes that happiness is based upon relevant concepts of positive feelings. Argyle (2001) considers happiness as satisfaction of life, positive affection, and negative affection. Some 
believe that positive affection in happiness is related with easy social relations in the format of a natural and satisfying relation (Sadeghi 2006).

Researchers following different theories and approaches thus tend to adopt different conceptualizations of happiness in their research. Happiness was seen by some analysts as a function related to positive feelings such as joy and satisfaction (Carr 2004; Griffin 2007). Similarly, Diener et al. (2005) proposed a broad concept of subjective well-being, referring to the encompassing occurrences of pleasant emotions, positive moods, and life satisfaction. Martin (2007) further extended his global levels of happiness to include overall and general satisfaction, out of control circumstances, and activities that inseminate positive moods and feelings. Argyle (2001) understanding of happiness as an individual type of feeling, however, included not only satisfaction and positive affection but also negative affection. Moreover, Lewinsohn et al. (1991) distinguished between the life satisfaction construct and happiness, arguing that happiness is an emotional state and can contribute to satisfaction. Happiness was also seen as a mechanism that propels one toward other gains (Linley et al. 2006). Kehle and Bray (2004) connected happiness with mental health. Their R.I.C.H. theory assumes that happy people demonstrate the interconnected of four characteristics: resources, intimacy, competence, and health.

With regard to happiness related to school, and as children spend a considerable amount of their time at school, it makes school an imperative part of their optimal growth as they acquire skills that will help them to effectively manage their environment (Baker et al. 2003). A variety of psychological, social, economic, physical, and organizational factors are shown to be associated with school children's happiness. Good moral qualities such as gratitude are important for increasing happiness (Lyubomirsky et al. 2005b). The correlation between feelings of children in school and the climate of the school was observed (Baker et al. 2003; Chafouleas and Bray 2004). Baker et al. (1997) found that when the school acts as a "personally supportive community", students felt more satisfied and their possibility of school completion increased. The principal's creativity and initiatives in including certain workshops for students, as well as student games, group sports, attractive school environment, and good readable books, assisted in improving happiness at school (Wolk 2008).

Many researches point to the education system (students, teachers, parents, school principals and support staff) as being most influential in making schools happy or unhappy places. An important criterion for happy schools is positive teacher attitudes and attributes such as kindness, enthusiasm and fairness, and the role in serving as inspiring, creative and happy role models for learners (Lee and Lee 2014). Research points to a need for schools to take this criterion into account in teacher recruitment and evaluation (i.e., teacher personality, attitude and ethics when hiring and assessing teachers) (Kim and Kim 2014; Van Hal et al. 2017).

Friendship is related to the quality of life of children when peer influence becomes significant. Lee (2016) analyzed the structural relationships between school-related psychological environment variables including teacher support, learning flow, and friendship and happiness of 870 students in Korean middle and high schools. Lee and Han (2000) noted that children who received high quality support from their peers had less social problems and discontent, along with the feeling of enhanced psychological wellbeing. Kim et al. study (2009) demonstrated that children who received greater love and 
emotional support from friends had a greater quality of life compared to those who were constantly bullied. Kocayörük and Telef (2015) also examined if parents' attachment exerted direct effects on children's happiness and found both direct and indirect influences of secure attachment relationships with parents on children's feelings of happiness.

Some empirical studies also identified categories that might influence school happiness. Students from different cultures is identified is noted as an important factor (Demir et al. 2012, 2013). With regard to student gender, most studies show that female students portray significantly higher scores (Dursun and Cesur 2016; Plagnol and Easterlin 2008; Ross and Mirowsky 2006; Stevenson and Wolfers 2009; Salavera et al. 2017). Mahon et al. (2010) found that there is no gender difference in the degree of happiness among students. Similarly, in a happiness-related school-based study of a sample of 1017 Norwegian students, no significant differences were found based on gender. School happiness studies also show that in general, younger students portray happier attitude and feelings (Dursun and Cesur 2016; Plagnol and Easterlin 2008; Salavera et al. 2017). However, older students (14-15 years) reported higher levels of unhappiness than younger students (13 years old) (Natvig et al. 2003). In South Korea, Han et al. (2012) compared the happiness of youth based on their age groups and found that the subjective psychological well-being of youth was lower than senior age groups. Our search could identify limited studies where no relations were found according to student categories such as gender or age (Mahon et al. 2010; Van Hal et al. 2017).

The literature review indicates that most previous studies reported the impact of teachers, friends, and learning separately and did not approach this integrative linkage in a fair manner. Some work on school happiness utilized regression analysis or simple descriptive statistics. This current study employed structural equation models (SEMs) that could simultaneously reflect potential measurement errors and better understand complex causal relationships as well as the direction of such relationships. The variables in the model were collected from an extensive search of related literature. The developed model was capable of systematically investigating the relationships among these variables in the final integrated model of factors that affect the happiness of school children.

\section{Context, methods and design}

This section presents the empirical context of this research and discusses the sample used, the instrument developed for the study, and the analytical methods used in addressing the objectives of the study.

\section{The context}

In Abu Dhabi, there are two systems of schooling-public and private schools. Public schools enroll mostly UAE nationals. In the public school system, boys and girls usually attend separate schools. However, in some cases, boys and girls attend the same school until the fifth grade. Private schools enroll both UAE nationals and non-nationals, where the percentage of non-national students in private schools is much higher than that of UAE national students. Private schools have different curriculum systems. There are a total of 14 different curriculums offered in these schools, including for example Indian, British, American curricula. It should be mentioned that certain nationalities of students prefer going to certain curriculums. 
With regard to location, Abu Dhabi Region has the largest number of schools (about 54.3\%), next comes Al Ain Region (36.7\%) and Al Dhafra Region (9.0\%). The Abu Dhabi Region is considered more city-type, $\mathrm{Al}$ Ain Region is both city-type and rural, while $\mathrm{Al}$ Dhafra Region is mixed too but covers the remote areas in the Emirate of Abu Dhabi.

\section{The sample}

The Happiness of School Children Survey questionnaire was posted on the main website of the ADEK during the third semester for 1 month in 2016. All schools were sent a memo as well as several reminders encouraging them to request their students to participate in the study. A total of 14,828 students from both public and private schools in Abu Dhabi participated in the survey (see Table 1). In general, it was observed that more students from the 5th, 3rd, and 6th grades participated in the study. Private school students were more enthusiastic about participating (72.8\% relative to $27.2 \%$ from public schools). The percentage of students in the sample from the three school districts (Abu Dhabi-71.9\%, $\mathrm{Al} \mathrm{Ain-22.1 \% ,} \mathrm{and} \mathrm{Al}$ Dhafra-6.0\%) is also relatively reflective of the population of students in these areas $(62.7 \%, 32.0 \%$, and $5.3 \%$, respectively). The percentages of male and female participation are also representative of the student population.

\section{The instrument and administration}

Several sources were reviewed before developing the survey instrument, including some similar studies that were conducted previously such as Ivens (2007), Kocayörük and Telef (2015), Lee (2016), Matthews et al. (2015), Robertson (2013), and Stiglbauer et al. (2013). The first part of the survey covered information regarding school location, school type, grade level, nationality, and gender. The subsequent part consisted of some

\section{Table 1 Sample of students}

\begin{tabular}{lc}
\hline Grade & \\
Grade 3 & $1828(13.5 \%)$ \\
Grade 4 & $1534(11.3 \%)$ \\
Grade 5 & $2146(15.8 \%)$ \\
Grade 6 & $1883(13.9 \%)$ \\
Grade 7 & $1536(11.3 \%)$ \\
Grade 8 & $1578(11.6 \%)$ \\
Grade 9 & $1289(9.5 \%)$ \\
Grade 10 & $918(6.8 \%)$ \\
Grade 11 & $545(4.0 \%)$ \\
Grade 12 & $322(2.4 \%)$ \\
Gender & \\
Male & $6212(45.5 \%)$ \\
Female & $7439(54.5 \%)$ \\
School type & \\
Public & $3735(27.2 \%)$ \\
Private & $10,012(72.8 \%)$ \\
School location & \\
Abu Dhabi & \\
Al Ain & \\
Al Dhafra & $9945(71.9 \%)$ \\
\hline
\end{tabular}


multiple choice questions regarding happiness (overall, relative to other friends and as a definition). Some items were related to the home (having fun, getting along, and spending time together with family members). The items reflect more the quality of time spent at home with parents, and other family members. The following section contained items related to student feelings about the self, other, and life. The last section included seven items dealing with school students and other matters.

A focus group comprising researchers, school administrators, and school psychologists was convened to review the instrument. The question items comprised various Likert scales of four, five, or seven points. In the final analysis, all items were converted to five-point Likert scales. Due to the objectives of the study, a total of 29 items were not used since they were related to the subjective well-being of students during the past week of filling the survey.

The instrument was administered online. Using the parent database at the ADEK, an email letter was sent to every parent requesting their consent to allow their children to participate in the online survey. Parents were provided with the survey link for them to give it to their children if they accepted the invitation. As a result, the children completed the survey at any time that they preferred. Such method was used to provide the children complete freedom to ensure others (parents or teachers) would not influence their responses.

\section{Analysis methods}

Descriptive statistics of all items were presented and analyzed. Three main dimensions were constructed. For each of the three dimensions of happiness, home and family, and school, a simple exploratory factor analysis (EFA) was performed to insure the unidimensionality of each of the three constructs. To ensure the reliability of each construct, Cronbach alpha was utilized.

The "home" dimension focuses on variables such as fun with the family, how family members get along, and time spent together with parents. It should be mentioned that the exploratory factor analysis (EFA) dropped only one home-related variable from further analysis (sometimes, I feel lonely at home). The "school" dimension includes variables reflecting satisfaction with the school, belonging to the school, looking forward to going to school, and feelings about other students in the school. The EFA dropped two variables from further analysis (I never feel safe at school, and I am treated fairly at school). The "happiness" dimension includes variables such as self-perception of happiness and level of happiness, happiness relative to others, feelings about life satisfaction, and having lots of friends.

For each measurement model, a confirmatory factor analysis (CFA) was also performed. An SEM was presented to portray the linkages and directions of the effects for the three constructs. For both CFA and SEM, the important statistics analyzed included the Chi square $\left(x^{2}\right)$, $p$ values, degrees of freedom, RMSEA, GFI, NFI, NNFI, AGFI, CFI, and RMR (Jöreskog and Sörbom 1989).

Multivariate Analysis of Variance (MANOVA) was employed to assess the differences of the three constructs of happiness, school, and home between student gender, grade level, type of school, and school location. MANOVA may yield some information to answer questions about the combined effect of the three dependent variables. It tests the 
null hypothesis of equality of vectors of means on multiple dependent variables across groups. For each category of students and each construct, the Wilk Lambda statistic was assessed. This statistic "examines whether groups are somehow different without being concerned with whether they differ on at least one linear combination of the dependent variables (Hair et al. 1998 pp. 351).

\section{Results}

Descriptive statistics of all used items in the study are exhibited in Table 2. For happiness, the highest means are recorded with respect to "I have lots of friends" and "my happiness is relative to my peers." With regard to school matters, the highest mean is recorded with regard to "I like my school" and "proud to belong to this school". For home and family, the highest mean belongs to "how family members get along".

EFA was performed to assess the reliability and validity of the three measurement scales. The application of EFA revealed that only one factor emerged, which indicates that the factors are unidimensional. The Cronbach alpha recorded were happiness (7.52), school (0.957), and home and family (0.705). These values are acceptable.

CFA corresponds to the measurement model of SEM. As a result, first, it is necessary to identify a valid set of measurement models linking a set of observed variables to a usually smaller set of latent variables. A CFA of each of the three constructs provides reasonable fit statistics. Table 3 provides the fit statistics with regard to each of the constructs. The home and family construct has only three variables; as a result, fit statistics are not available.

Table 4 shows the covariance matrix of the variables that were used in the SEM analysis. The final SEM model is provided in Fig. 1. Several steps were followed to arrive at

Table 2 Descriptive statistics

\begin{tabular}{llll}
\hline Code & Dimension and variables & Mean & $\begin{array}{c}\text { Standard } \\
\text { deviation }\end{array}$ \\
\hline Happiness & & 3.65 & 1.317 \\
Q9 & In general, I consider myself happy & 3.87 & 1.686 \\
Q10 & My happiness relative to my peers & 3.83 & 1.178 \\
Q17_1 & Life is good at the moment & 3.39 & 1.720 \\
Q11 & Happiness and enjoying life & 3.90 & 1.170 \\
Q17_19 & I have lots of friends & & \\
School matters & & 3.59 & 1.358 \\
Q18_1 & This is an excellent school & 3.70 & 1.289 \\
Q18_2 & I like my school & 3.68 & 1.290 \\
Q18_3 & Proud to belong to this school & 3.54 & 1.332 \\
Q18_4 & Locking forward to coming to school in the morning & 3.49 & 1.294 \\
Q18_5 & Students in this school are happy to be here & 3.54 & 1.331 \\
Q18_6 & I recommend this school to my friends & 3.59 & 1.337 \\
Q18_7 & Overall I am satisfied with this school & & \\
Home and family & & 3.30 & 0.877 \\
Q13 & How much fun with Family & 4.34 & 0.938 \\
Q14 & How family members get along & 3.37 & 1.086 \\
Q15 & Parent's time spent with you & &
\end{tabular}

All mean (average) values are from minimum 1 to maximum 5 
Table 3 Fit statistics of each of the constructs (CFA)

\begin{tabular}{lrlllllllll}
\hline & $\mathbf{X}^{\mathbf{2}}$ & $\boldsymbol{d f}$ & RMSEA & $\mathbf{P}$ & NFI & NNFI & GFI & AGFI & CFI & RMR \\
\hline Happiness & 7.02 & 3 & 0.010 & 0.07125 & 0.999 & 0.998 & 0.999 & 0.998 & 0.999 & 0.00318 \\
School matters & 14.09 & 6 & 0.018 & 0.01900 & 0.999 & 0.997 & 0.999 & 0.998 & 0.999 & 0.00641 \\
Home and family & & & & & & & & & & \\
\hline
\end{tabular}

this final figure. The steps involved the inclusion of the error covariance between variables, adding paths between latent constructs, and checking for the largest standardized residuals. The most important results have to do with fit statistics obtained by running the final SEM model. The fit statistics are provided in Table 5. The values indicate that the portrayed model enjoys good characteristics. The RMSEA is 0.0265 , well below the threshold of 0.05 , and the value of $\left(x^{2} / d f\right.$ of 2.733) is below the threshold of 3.0. All other indexes are good (Jöreskog and Sörbom 1989).

Table 6 provides the standardized estimates and the $t$ values of the variables in the SEM model. All $t$ values are indicative of a good hypothesized SEM model. These results indicate that all the estimates (loadings) are statistically significant at a 0.05 level of significance. Consequently, the indicators for school status and home and family attitude seem to achieve an acceptable level of construct validity. The results imply that both school and home and family exert a direct and statistically significant influence on happiness. The effect from school on happiness is 0.57 with a t value of 47.53 . It should be noted that the school construct consisted of attitude and feeling toward the school in general and students in the school. The variables with the highest standardized estimate (importance) are "I like my school" (0.94), "this is an excellent school" (0.93), and "proud to belong to this school" (0.92)." In addition, the model shows that home has an extra significance by exerting an indirect force on happiness through its influence on school, with an indirect effect of 0.2451 . As a result, the total effect is 0.6751 .

Another significant result is that home affects both school (0.43) and happiness (0.55). This reflects the importance of the nature of relationships at home (having fun with each other, getting along with each other, and spending time with parents). With regard to the happiness construct, the most important variable deals with having lots of friends, with an estimate of 0.70 . Other important features of happiness deal with attitude toward life in general and student's own perception of happiness.

Results showed a statistically significant multivariate effect for student age (grade level), nationality, type of school, and school location with regard to all three constructs of school, home, and happiness. Table 7 shows the MANOVA results for three significant constructs. The multivariate tests show that Wilks' Lambda is significant for three constructs across all five categories, but not significant with regard to student nationality. The composite means of each of these groups for each of the three dimensions reflect the differences.

With regard to the "home" satisfaction scores, we note that students in Abu Dhabi show higher satisfaction than that of Al Ain and Al Dhafra (3.6996, 3.6527, and 3.4032 relatively). We also notice that private school students show a higher "home" satisfaction score than their public school counterparts (3.7162 compared to 3.5505). Non-national students showed significantly higher scores with regard to two variables (Q14 and Q15). 


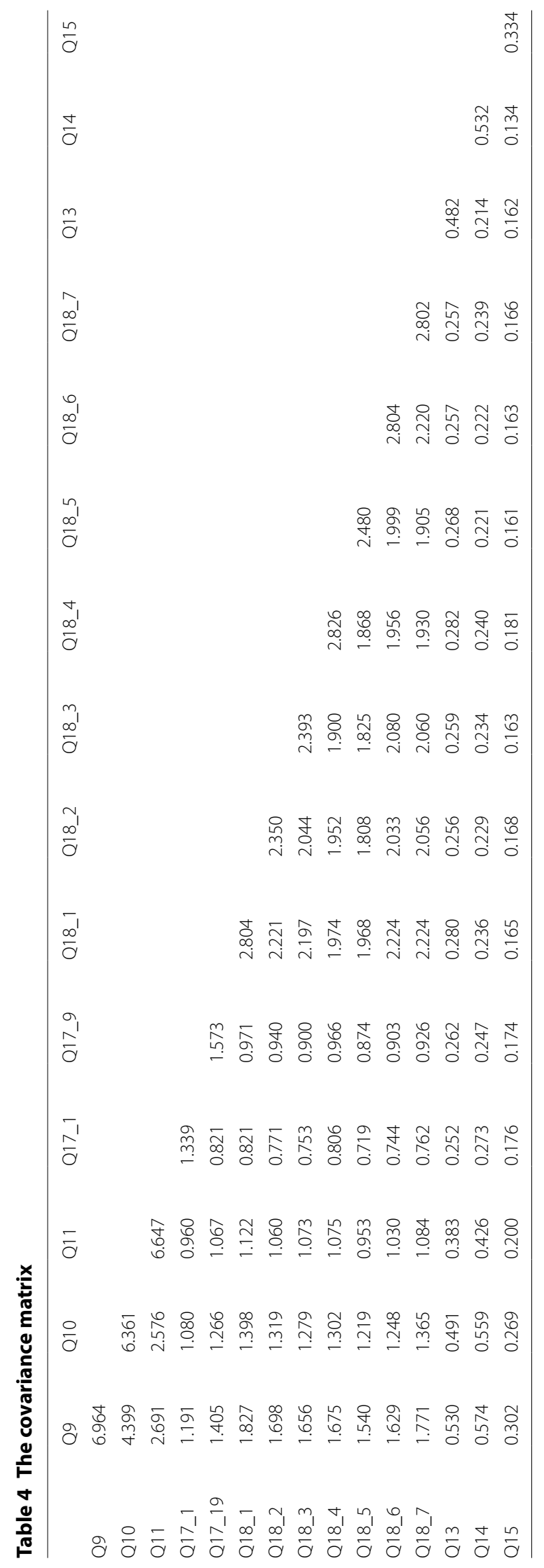




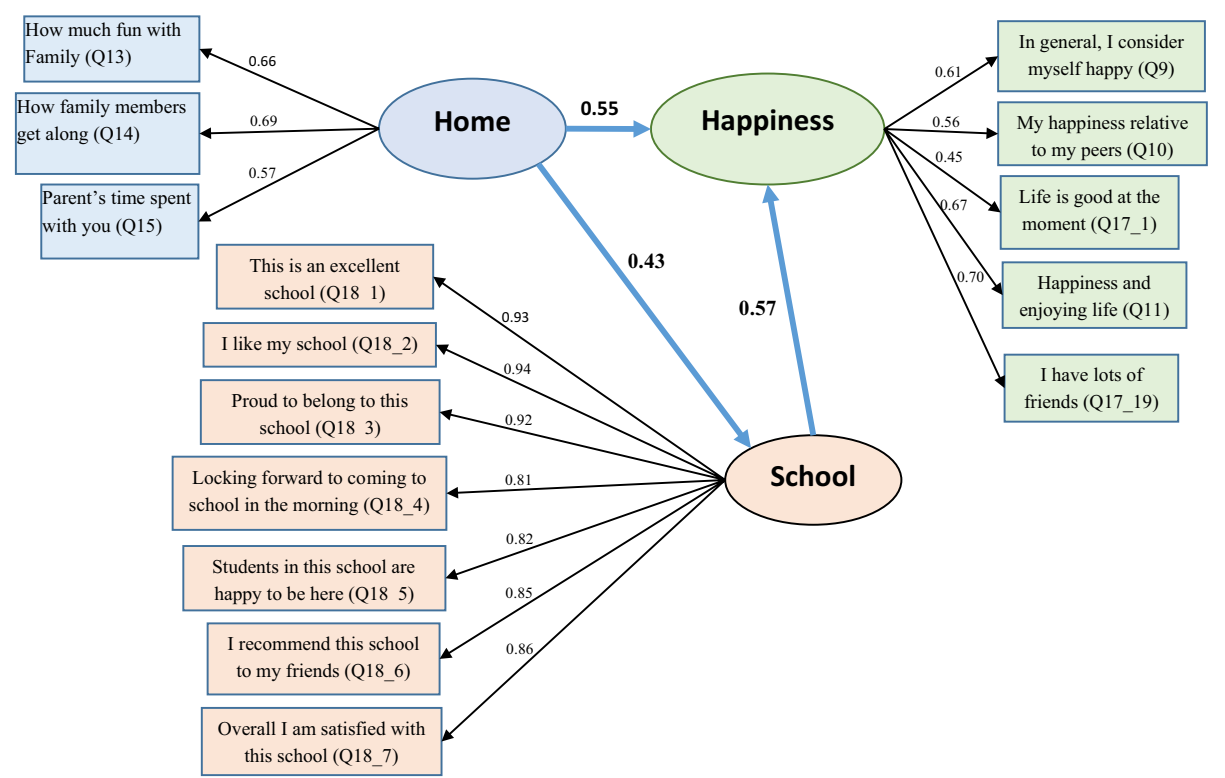

Fig. 1 The general structural equation model

Table 5 The general model fit statistics

\begin{tabular}{llllllllll}
\hline Chi square $x^{\mathbf{2}}$ & Degrees of freedom $(\boldsymbol{d} \boldsymbol{f})$ & $\boldsymbol{x}^{\mathbf{2}} / \boldsymbol{d f}$ & RMSEA & NFI & NNFI & GFI & AGFI & CFI & RMR \\
\hline 202.261 & 74 & 2.733 & 0.0265 & 0.994 & 0.993 & 0.993 & 0.991 & 0.995 & 0.0486
\end{tabular}

Table 6 Final structural equation model results

\begin{tabular}{llll}
\hline Code & Variables & $\begin{array}{l}\text { Standardized } \\
\text { estimate }\end{array}$ & t-value \\
\hline Happiness & & & \\
Q9 & In general, I consider myself happy & 0.61 & 78.70 \\
Q10 & My happiness relative to my peers & 0.56 & 74.78 \\
Q17_1 & Life is good at the moment & 0.67 & 58.12 \\
Q11 & Happiness and enjoying life & 0.45 & 48.84 \\
Q17_19 & I have lots of friends & 0.70 & 59.93 \\
School matters & & & \\
Q18_1 & This is an excellent school & 0.92 & 200.65 \\
Q18_2 & I like my school & 0.93 & 204.24 \\
Q18_3 & Proud to belong to this school & 0.92 & 196.33 \\
Q18_4 & Locking forward to coming to school in the morning & 0.81 & 129.70 \\
Q18_5 & Students in this school are happy to be here & 0.84 & 140.14 \\
Q18_6 & I recommend this school to my friends & 0.85 & 158.55 \\
Q18_7 & Overall I am satisfied with this school & 0.86 & 162.14 \\
Home and Family & & & \\
Q13 & How much fun with family & 0.66 & 64.51 \\
Q14 & How family members get along & 0.64 & 65.98 \\
Q15 & Parent's time spent with you & 0.49 & 46.85 \\
\hline
\end{tabular}


Table 7 MANOVA Wilks' Lambda for each construct and student category

\begin{tabular}{llll}
\hline & Wilks' Lambda & F value & Significance \\
\hline Student nationality & & & \\
Happiness & 0.060 & 36.92 & 0.0001 \\
School matters & 0.981 & 31.348 & 0.0001 \\
Home and family matters & 0.952 & 24.814 & 0.0001 \\
Student gender & & & \\
Happiness & 0.993 & 8.276 & 0.0001 \\
School matters & 0.997 & 4.435 & 0.0001 \\
Home and family matters & 0.996 & 16.159 & 0.0001 \\
Student grade level & & & 0.0001 \\
Happiness & 0.936 & 16.635 & 0.0001 \\
School matters & 0.871 & 25.473 & 0.0001 \\
Home and family matters & 0.944 & 25.863 & 0.0001 \\
Student type of school & & & 0.0001 \\
Happiness & 0.994 & 13.047 & 0.0001 \\
School matters & 0.994 & 10.660 & \\
Home and family matters & 0.966 & 14.482 & 0.0001 \\
School location & & & 0.0001 \\
Happiness & 0.993 & 8.267 & 0.0001 \\
School matters & 0.992 & 6.495 & 9.695 \\
Home and family matters & 0.978 & & \\
\hline
\end{tabular}

With regard to age, younger students show more "home" satisfaction than older students. For example, the composite "home" scores for cycle one students is (3.7418), for cycle two students (3.6387), and for cycle three students is (3.4597). Results also show that girls are scoring more "home" satisfaction than boys (3.7089) compared to (3.6306).

For the "school"-related composite scores, we note that Abu Dhabi leads with $\mathrm{Al}$ Dhafra second and Al Ain third (3.6457, 3.5234, and 3.4267 relatively). With regard to school type, private schools score 3.6183 and public schools score 3.5162 . With regard to age, overall scores related to positive feelings about the school go down as students' progress from grade to higher grade, as cycle one students score the highest $(3.8965,3.3512$, and 2.9275, respectively). Meanwhile, girls score higher than boys (3.6027 and 3.5802, respectively).

For the "happiness" composite scores, students in Abu Dhabi show the highest happiness, followed by students in $\mathrm{Al}$ Ain and Al Dhafra (3.9559, 3.8286, and 3.6944, respectively). Public school students score 3.944 , while private school students score 3.826 . With regard to student gender, female students show significantly higher happiness scores with regard to all five variables. Cycle one students score 4.0347), cycle two 3.817, and cycle three 3.633. Mixed results are seen when it comes to student nationality, where two items record higher happiness for UAE nationals (Q9 and Q10) and two of the items show higher happiness for non-national students (Q17_1 and Q17_9).

\section{Discussions}

As suggested by Morgan (2014) and Park et al. (2012), the current study used an integrated approach that utilized structural equation modeling to better understand the linkages and direction of influences between the hypothesized constructs. The SEM 
hypothesis may simultaneously reflect potential measurement errors and determine complex causal relationships.

The results of this current study are consistent with research that suggests that the causes of happiness are multivariate. Results reveal that there is a positive and significant influence of both home and school on student happiness in public and private schools in Abu Dhabi. Results confirm both direct and indirect links of the influence of home on happiness. Generally, these findings are in consonance with the theoretical foundation of the issue. In general, it also provides support to other studies including Ivens (2007), Kim and Kim (2014), Kocayörük and Telef (2015), Lee and Lee (2014), Park et al. (2000), and Parker and Asher (1989).

Considering that Abu Dhabi school children spend more than $8 \mathrm{~h}$ a day at school, it is important to explore school-related variables that influence their happiness. The school-related environment variables used in this study involved general school attitude, friends, satisfaction, and learning. The seven school-related variables enjoyed the highest standardized estimates relative to all other variables. The values ranged from a low of 0.82 to a high of 0.94 . As direct effects on happiness, school-related variables exhorted the highest direct effect of 0.57 . The impact and importance of such variables on happiness have been reported by others (Kim and Kim 2014; Lee 2016). Such results might demand that schools promote student happiness and set happiness as a goal of schooling. School professionals in Abu Dhabi should establish a mechanism to monitor students' happiness in schools. Huebner et al. (2006) have suggested that schools could provide many interventions that could be educational, social-emotional, and medical. It is useful to note that in their comprehensive review of studies in promoting positive psychology including happiness, well-being, and life satisfaction, McCabe et al. (2011) presented specific techniques that are more amenable to school-based practice.

Results show that female students portray significantly higher scores with regard to all three constructs. Such results are consistent with other relatively similar school studies (Dursun and Cesur 2016; Plagnol and Easterlin 2008; Ross and Mirowsky 2006; Stevenson and Wolfers 2009). The three constructs also show that students at early ages show more positive scores (Dursun and Cesur 2016). Results contradict outcomes of a happiness research in Belgium schools where no relations were found between happiness, and sex or age (Van Hal et al. 2017).

The present study adopted a positive perspective on school experiences and the general functioning of Abu Dhabi school children and described a positive feeling of happiness. Results show that positive school experiences promoted happiness. The positive effect of school experiences on happiness corroborates previous findings that also considered other variables (Natvig et al. 2003; Vieno et al. 2004).

Looking at the model and results closely, we note that what happens at "home" has a significant influence on both "school" and overall "happiness". Having fun with other family members, getting along fine with other members of the family, and spending more time with parents spell directly to the school and what happens there. As a result, satisfaction with the school is affected where friends also play an important role. In an abstract way, the model shows that it seems that what is measured by "home" affects the satisfaction with "school". In addition, both "home" and "school" overwhelmingly affect overall "happiness". 


\section{Conclusions, implications and future directions}

It is important to know that understanding the relationship of happiness in schools to contexts is important. There is limited understanding of contextual influences on happiness. The problem addressed in this manuscript is important and could potentially have implications for development of theory and interventions to promote children's happiness.

Structural equation modeling and MANOVA were employed to examine the association between latent constructs. SEM was executed assessing the hypothesized model. MANOVA analysis was used to compare the differences between the different categories of students. It was performed to assess the effect of gender, age, grade level, and type of school.

The proposed structural relationship investigated in this study shows that both school and home variables directly influence the happiness of school children. In addition, home indirectly influences the happiness of school children through the school. The results of this study, which demonstrate how school-related variables along with family oriented variables interact to increase the happiness of Abu Dhabi school children, provide timely implications regarding how to increase the happiness of those children. In addition, the results provide guidance and support to help school leadership and policy makers in creating ways to increase their children's happiness.

The goodness of fit of the SEM that integrates school matters and family related variables and their impact on school children happiness is validated. With regard to the significance of school matters, the results are consistent with previous studies. However, many studies also confirmed the effect of teacher support on student happiness (Kim et al. 2009; Lee and Lee 2014). Future research may redesign the questionnaire to include teacher support as a main construct.

Results show significant differences in happiness-related scores according to gender, age, nationality, type of school, school location, and. Such outcomes might require more in-depth look at the causes of such variations. School policy makers should pay extra attention to such differences, as different strategies to enhance happiness between the student categories might be required.

The study had some limitations. The study used convenience sampling which is a type of non-probability sampling technique. Such sampling methods often might lead to biases as it can lead to the under-representation or over-representation of particular groups within the school sample. Future studies should be more careful in this regard and use more efficient type of sampling where all categories are represented accordingly.

Future studies should also pay attention to the fact that stronger case should be made for any predictions about direction of effect between the constructs used in this study. It seems equally plausible that someone who is happy will have a better experience at home or at school than someone who is not. In this regard, the SEM model was run with the arrow directions changed from happiness to school and home instead. Results yielded Chi square $X^{2}$ of 3009.5, with 75 degrees of freedom, and RMSEA of 0.1058 . The results of the original model presented are much better than the results of this trial run.

Results of this study call for more understanding of the contextual influences of the significant differences that results between boys and girls, type of school, student grade level (age), and location of the school. Further research is needed to explore what the 
contextual influences might be. Future research should explore the significance of some other social variables which are linked to the results of this study.

It may also be that there are other factors that influence both school/home experience and happiness but are not measured in this study. Future study designs should help to get past this question. The current study used 15 items. However, the study did not use some items or questions that were used in other studies. Including those items may help if they can be used to measure happiness in separate or as longitudinal measures of happiness.

MANOVA proved to identify the presence of many different groups in the study (gender, nationality, grade, age, etc.). In future research, it should be acknowledged that the use of Hierarchical linear modeling (HLM) might be more suitable than simple SEM. HLM applies when the observations in a study form groups in some way and the groups are randomly selected (Raudenbush and Bryk 2002). As a result, data could be grouped because multiple time points are nested within each student group or school. For example, there could be multiple students per school, multiple schools per city, or multiple cities per region. HLM applies to the situation when they represent a random factor rather than a fixed factor.

We should also mention that the relatively smaller sample size of public school students relative to private schools students limits the generalizability of the findings. Understanding and explaining what "happiness" may mean to school children may vary over a period of time. In this study, data were collected from each student on a single occasion. Continued data collection periodically or over an extended period of time may have more realistic benefits. Future studies should explore personality traits of school children as well as student family's social economic status. It could also have explored the student's level of performance in school. As a result, we could not link personality traits or performance with the meanings of "happiness." Undertaking such a task may provide enriching insights for school policy makers. Meanwhile, understanding the link between school recreational activities, extracurricular activities, and interests in STEM and children's "happiness" in a better manner could have been of significant interest to both schools and parents. Future research might also consider including phrases and other aspects of children's experiences of treatment (i.e., being bullied) in school.

Declaration

This manuscript has been published as a working paper article earlier on: https://www.adek.abudhabi.ae/en/Pages/ default.aspx

\section{Authors' contributions}

All authors have participated sufficiently in the work to take public responsibility for appropriate portions of the content. All authors of this article have made substantive intellectual contributions to the article. Both MB and GY have made substantial contributions to conception and design, and acquisition of data, and analysis and interpretation of data. Both performed the extensive structural equation model, and ensured the model fit statistics. Both AR and AS performed extensive statistical analysis on the data, and been involved in drafting and checking the draft. Both worked on using the special software dealing with TIMSS data to be converted to SPSS for further analysis. AA, and MB been involved in drafting the manuscript and revising it critically for important intellectual content. Both participated in its design and coordination. All authors helped to draft the manuscript. AA gave final approval of the version to be published. All authors read and approved the final manuscript.

Competing interests

The authors declare that they have no competing interests.

\section{Funding}

The authors declare, that in the past 5 years they have not received reimbursements, fees, funding, or salary from an organization that may in any way gain or lose financially from the publication of this manuscript, either now or in the future. 


\section{Publisher's Note}

Springer Nature remains neutral with regard to jurisdictional claims in published maps and institutional affiliations.

Received: 25 April 2017 Accepted: 7 December 2018

Published online: 18 December 2018

\section{References}

Al-Yasin, M. (2001). Happiness in school. Journal of Education., 33(1), 67-87.

Argyle, M. (2001). The psychology of happiness. London: Routledge.

Baker, J. A., Dilly, L. J., Aupperlee, J. L., \& Patil, S. A. (2003). The developmental context of school satisfaction: Schools as psychologically healthy environments. School Psychology Quarterly, 18(2), 206-221.

Baker, J. A., Terry, T., Bridger, R., \& Winsor, A. (1997). Schools as caring communities: A relational approach to school reform. School Psychology Review, 26, 586-602.

Carr, A. (2004). Positive psychology: The science of happiness and human strengths. London: Brunner Routledge.

Chafouleas, S. M., \& Bray, M. A. (2004). Introducing positive psychology: Finding a place within school psychology. Psychology in the Schools, 41(1), 1-5.

Datu, J., King, R., \& Valdez, J. (2017). The academic rewards of socially-oriented happiness: Interdependent happiness promotes academic engagement. Journal of School Psychology, 61, 19-31.

Demir, M., Bilyk, N., Jaffar, J., \& Ariff, M. (2012). Social skills, friendship and happiness: A cross-cultural investigation. The Journal of Social Psychology, 152, 379-385.

Demir, M., Dogan, A., \& Procsal, A. (2013). I am so happy 'cause my friend is happy for me: Capitalization, friendship, and happiness among US and Turkish college students. The Journal of Social Psychology, 153(2), 250-255.

Diener, E. (2000). Subjective well-being: The science of happiness and a proposal of a national index. American Psychologist, 55, 34-43.

Diener, E., Lucas, R. E., \& Oishi, S. (2005). Subjective well-being: The science of happiness and life satisfaction. In C. R. Snyder \& S. J. Lopez (Eds.), Handbook of positive psychology (pp. 63-73). New York: Oxford University Press.

Dursun, B., \& Cesur, R. (2016). Transforming lives: The impact of compulsory schooling on hope and happiness. Journal of Population Economics, 29, 911-956.

Faure, E. (Ed.). (1972). Learning to be: The world of education today and tomorrow. In International Commission on the Development of Education. Paris, UNESCO. Retrieved from http://www.unesco.org/education/pdf/15_60.pdf.

Frey, B. S., \& Stutzer, A. (2002). Happiness and economics: How the economy and institutions affect human wellbeing. NJ: Princeton University Press.

Griffin, J. (2007). What do happiness studies study? Journal of Happiness Studies, 8, 139-148.

Guilherme, A., \& de Freitas, A. (2017). 'Happiness education': A pedagogical-political commitment. Policy Futures in Education, 15(1), 6-19.

Hair, J. F., Jr., Anderson, R. E., Tatham, R. L., \& Black, W. C. (1998). Multivariate data analysis (5th ed.). Upper Saddle River: Prentice Hall.

Han, M., Choi, I., Kim, B., Lee, H., Kim, K., \& Ryu, S. (2012). Happiness of Korean adolescence: Age-based comparison. Korean Journal of Youth Studies, 19, 217-235.

Huebner, E. S., Gilman, R., \& Suldo, S. M. (2006). Life satisfaction. In G. Bear \& K. Minke (Eds.), Children's needs III (pp. 357-368). Bethesda: National Association of School Psychologists.

Ivens, J. (2007). The development of a happiness measure for school children. Educational Psychology in Practice, 23(3), 221-239.

Jöreskog, K., \& Sörbom, D. (1989). LISREL7: A guide to the program and applications (2nd ed.). Chicago: SPSS Inc.

Kahneman, D., \& Tverski, A. (Eds.). (2000). Choices, values and frames. New York: Cambridge University Press.

Kehle, T., \& Bray, M. (2004). RICH theory: The promotion of happiness. Psychology in the Schools, 41(1), 43-49.

Kim, J., \& Kim, H. (2014). Effects of teacher perceived student-teacher relationship and changes in student perceived student-teacher relationships on academic achievement mediated by school happiness and classroom engagement. Korean Journal of Youth Studies, 21, 285-315.

Kim, J., Kim, E., \& Hong, S. (2009). Effects of self-determination on the academic achievement in Korean middle school students. Korean Journal of Educational Psychology, 20, 243-264.

Kocayörük, E., \& Telef, B. B. (2015). The Relations between attachment to parents and school happiness: Positive and negative experiences as a mediator. In Paper presented at European Educational Research Association Conference (ECER 2015 Education and Transition), September 7-11, Budapest.

Lee, J. (2016). Impact of school psychological environment variables on happiness of Korean youths. Japanese Psychological Research, 58(4), 310-319.

Lee, E., \& Han, M. (2000). A study on the factors related to happiness of youth: Focusing on the mental health side. In Paper presented at the Korean Association of Adolescent Welfare Spring Conference, 71-99, Seoul, South Korea.

Lee, H., \& Lee, J. (2014). Effects of teacher's attachment perceived children to school happiness of children: The mediated effects of learning flow and peer competence. Youth Facility and Environment, 12, 81-91.

Lewinsohn, P. M., Redner, J. E., \& Seeley, J. R. (1991). The relationship between life satisfaction and psychosocial variables: New perspectives. In F. Strack, M. Argyle, \& N. Schwarz (Eds.), Subjective well-being: An interdisciplinary perspective (pp. 141-169). Oxford: Pergamon.

Linley, P. A., Joseph, S., Harrington, S., \&Wood, A. M. (2006). Positive psychology: Past, present and (possible) future. Journal of Positive Psychology, 1(1), 3-16.

Lykken, D. T. (1999). Happiness: What studies on twins show us about nature, nurture and the happiness set-point? New York: Golden Books. 
Lyubomirsky, S., King, L., \& Diener, E. (2005a). The benefits of frequent positive affect: Does happiness lead to success? Psychological Bulletin, 131, 803-855.

Lyubomirsky, S., Sheldon, K. M., \& Schkade, D. (2005b). Pursuing happiness: The architecture of sustainable change. Review of General Psychology, 9(2), 111-131.

Mahon, N. E., Yarcheski, A., \& Yarcheski, T. J. (2010). Happiness as related to gender and health in early adolescents. Clinical Nursing Research, 14(2), 175-190

Martin, M. W. (2007). Happiness and virtue in positive psychology. Journal for the Theory of Social Behavior, 37(1), 89-103.

Matthews, N., Kilgour, L., Christian, P., Mori, K., \& Hill, D. (2015). Understanding, evidencing, and promoting adolescent well-being: An emerging agenda for schools. Youth \& Society, 47(5), 659-683.

McCabe, K., Bray, M., Kehle, T., Theodore, L., \& Gelbar, N. (2011). Promoting happiness and life satisfaction in school children. Canadian Journal of School Psychology, 26(3), 177-192.

McDowell, I., \& Newell, C. (1996). Measuring health: A guide to rating scales and questionnaires (2nd ed.). New York: Oxford University Press.

Moos, L., Krejsler, J., Kofod, K., \& Jensen, B. (2005). Successful school principal-ship in Danish schools. Journal of Educational Administration, 43(6), 563-571.

Morgan, R. (2014). The children's happiness scale. Office for Standards in Education, Children's Services and Skills (OFSTED): Manchester, UK.

Natvig, G. K., Albrektsen, G., \& Qvarnstrom, U. (2003). Associations between psychosocial factors and happiness among school adolescents. International Journal of Nursing Practice, 9, 166-175.

Oreopoulos, P. (2007). Do dropouts drop out too soon? Wealth, health and happiness from compulsory schooling. Journal of Public Economics, 91, 2213-2229.

Park, Y. S., Kim, U. C., Chung, K. S., Lee, S. M., Kwon, H. H., \& Yang, K. M. (2000). Causes and consequences of life-satisfaction among primary, junior high, and senior high school students. Korean Journal of Health Psychology, 5, 94-118.

Park, Y. S., Kim, U. C., \& Han, K. H. (2012). Factors influencing the perceived level of happiness among adolescents: With specific focus on family, school and leisure life. Korean Journal of Youth Studies, 19, 334.

Parker, J., \& Asher, S. (1989). Friendship and friendship quality in middle childhood: Links with peer group acceptance and feelings of loneliness and social dissatisfaction. Developmental Psychology, 29, 611-621.

Plagnol, A., \& Easterlin, R. (2008). Aspirations, attainments, and satisfaction: Life cycle differences between American women and men. Journal of Happiness Studies, 9, 601-619.

Raudenbush, S., \& Bryk, A. (2002). Hierarchical Linear Models: Applications and data analysis methods (2nd ed.). Newbury Park: Sage.

Roberts, M. C., Brown, K. J., Johnson, R. J., \& Reinke, J. (2005). Positive psychology for children: Development, prevention and promotion. In C. R. Snyder \& S. J. Lopez (Eds.), Handbook of positive psychology (pp. 663-675). New York: Oxford University Press.

Robertson, J. (2013). Self-concept, school satisfaction, and other selected correlates of subjective well-being for advanced high school learners enrolled in two challenging academic settings. Journal for the Education of the Gifted, 36(4), 461-486.

Ross, C., \& Mirowsky, J. (2006). Sex differences in the effect of education on depression: Resource multiplication or resource substitution? Social Science and Medicine, 63, 1400-1413.

Sadeghi, A. (2006). Effective factors in creating a happy school. Tehran: Research Institution of Education Innovation.

Sagiv, L., Roccas, S., \& Hazan, O. (2004). Value pathways to well-being: Healthy values, valued goal attainment, and environmental congruence. In A. Linley \& S. Joseph (Eds.), Positive psychology in practice (pp. 68-85). Hoboken: Wiley.

Salavera, C., Usán, P., Pérez, S., Chato, A., \& Vera, R. (2017). Differences in happiness and coping with stress in secondary education students. Procedia Social and Behavioral Sciences, 237, 1310-1315.

Seligman, M., Ernst, R., Gillham, J., Reivich, K., \& Linkins, M. (2009). Positive education: Positive psychology and classroom interventions. Oxford Review of Education, 35(3), 293-311.

Sheldon, K. M., \& Lyubomirsky, S. (2004). Achieving sustainable new happiness: Prospects, practices, and prescriptions. In A. Linley \& S. Joseph (Eds.), Positive psychology in practice (pp. 127-145). Hoboken: Wiley.

Soleimani, N., \& Tebyanian, E. (2011). A study of the relationship between principals' creativity and degree of environmental happiness in Semnan high schools. Procedia Social and Behavioral Sciences, 29, 1869-1876.

Stevenson, B., \& Wolfers, J. (2009). The paradox of declining female happiness. American Economic Journal Economic Policy, 1, 190-225.

Stiglbauer, B., Gnambs, T., Gamsjäger, M., \& Batinic, B. (2013). The upward spiral of adolescents' positive school experiences and happiness: Investigating reciprocal effects over time. Journal of School Psychology, 51, 231-242.

UNESCO (2014). Learning to live together. Education policies and realities in the Asia-Pacific. Paris: UNESCO. Retrieved from http://unesdoc.UNESCO.org/images/0022/002272/227208E.pdf.

UNESCO (2016). Happy schools—a framework for learner well-being in the Asia Pacific. Retrieved from http://unesd oc.unesco.org/images/0024/002441/244140e.pdf.

Van Hal, G., Bruggeman, B., \& Bruggeman, H. (2017). Happy teachers and happy school children: Going hand in hand. European Journal of Public Health, 27 (supplement 3).

Veenhoven, R. (2006). How do we assess how happy we are? Tenets, implications and tenability of three theories. Paper presented at conference on 'New Directions in the Study of Happiness: United States and International Perspectives', October 22-24, University of Notre Dame, USA.

Vieno, A., Santinello, M., Galbiati, E., \& Mirandola, M. (2004). School climate and well-being in early adolescence: A comprehensive model. European Journal of School Psychology, 2, 219-238.

Weissberg, R., Kumpfer, \& Seligman, M. (2003). Prevention that works for children and youth: An introduction. American Psychologist, 58, 425-432.

Wolk, S. (2008). Joy in school. Educational Leadership, 66(1), 8-15. 